Cristiana Senigaglia

University of Trieste, Italy

\title{
THE LOGIC OF RESENTMENT IN THE GLOBALIZED WORLD
}

\section{Nietzsche's notion of resentment and the logic of double negation}

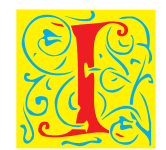

$\mathrm{n}$ his work On the Genealogy of Morals, Nietzsche analyzes the notion of resentment and its consequences on human action. For him, resentment is a condition which affects individuals who feel weak and threatened and who are not capable or strong enough to unfold in a positive way the energies of life. In this sense, resentment can be considered as a form of hatred growing from powerlessness. It is generated by a profound sentiment of dissatisfaction with one's own condition of existence, and this feeling of discontent is projected towards the external and associated with a determinate person or group of people, made responsible for the unsatisfactory self-image. In reality, resentment can be produced by social, economic, and intellectual disparities. The decisive aspect is, however, that the subjective feeling is clearly prevailing over the objective condition and state of things. Without the feeling of discontent and weakness, resentment would not conspicuously appear.

The shifting of guilt and responsibility to an external agent (mostly a collective agent, if the phenomenon is to be considered as socially relevant) is an essential complementary issue entailed in resentment, and it depends, according to Nietzsche, on a logical inference: "I suffer: it must be somebody's fault." Thus, instead of analyzing one's own condition, the resentful man concentrates on an external subject which is made accountable for one's own misfortune. This is due to the fact that the resentful man already possesses a devaluated im-
\end{abstract}

1 F. Nietzsche, The Genealogy of Morals, trans. H. B. Samuel, New York: Boni and Liveright, 1921, III-15, 135. 
pression of the self (first negation). Thus, the revaluation of his self can be performed only indirectly, by ascribing bad qualities and behavior to someone else, i.e. the presumed guilty (second negation). Being burdened with the sentiment of inadequacy, the resentful man can recover from it exclusively by a radical double negation (a negation of negation which does not recuperate any positive meaning from the negative moment), which confers on him a positive value only in opposition to the negative other.

This double negation in the form of radical opposition has momentous consequences also from a psychological and moral vantage point, since the negative moment is charged with a correspondingly negative value judgment. The negation represented by the "targeted" other, estimated as the guilty and responsible counterpart, is from a psychological view-point the chief reason for one's own defeat and devaluation, and from a moral standpoint the embodiment of the bad and the evil. This implies that there is no dialogical possibility of argument or confrontation, but the negative other is someone (or something, considering the innate tendency to objectification) whose even remote existence constitutes a present and perceptible threat. On the other hand, the consideration of this other as the identified guilty provides a revaluation of one's own self and a temporary relief, but it is accompanied by a permanent sense of frustration by being impeded from the intrinsic unfolding of one's own energies and capabilities because of the influence of the hindering other. Thus, the negative other becomes the focus of one's own attention, the permanent point of reference as well as the inexorable negating limit.

According to Nietzsche, this causes an attitude and an agency which are intrinsically reactive, i.e. always conceived in the relation to the negative "other". In fact, Nietzsche delineates the reactive agency by means of an opposition, which is centered on the conceptual pair active-reactive and is respectively traced back to the noble and the resentful man. In Nietzsche's understanding, active agency implies being substantially concerned with one's own interests, objectives, and capacities. From this perspective, the motivation of agency is self-centered and self-reliant, and the ends aimed at are self-determined. In doing so, active agency is essentially positive and self-strengthening, and it pursues an enhancement of the self which originates from the inside.

By contrast, reactive agency is always aroused and provoked from the outside. The resentful man, being constantly concerned with the negative and hindering other, is always determined by his agency and acts in the form of the reply, without conceiving of something really spontaneous and original. 
Moreover, as the other is perceived as hostile and guilty of impeding the development of the self, the resentful man is predominantly motivated by a form of revenge which is not actuated as an immediate reaction or impulse, but as a strategy of delay and ambush. Surely, revenge becomes creative and produces series of actions, but these are not self-determined and self-strengthening, since they are focused in and conditioned by the external, negative other, and they spring up from a position which "says no from the very outset to what is outside itself, different from itself, and not itself."

As a consequence, the logic of double negation performed by resentment shows itself to be intrinsically destructive: all its objectives and proposals are centered on the elimination or disempowerment of the guilty other and forgetting the person's own potential and aims. Moreover, this externally motivated reaction is only momentarily relieving and in reality steadily accompanied by frustration, since it bases on a negative image of the self which can be overthrown only by the persistence of the negative other. This has the internally contradictory and ironic consequence that the other cannot be destroyed, and even if he were destroyed, he would persist as an ineradicable counter-image, since the identity and the agency of the resentful man are constitutively reliant on it. When the targeted "other" disappears or loses his conflictive potential, the resentful man cannot break the logic of the radical double negation and needs a surrogate for his identity-building structure: either the enemy image is perpetuated as a fictive menacing presence, or it is substituted by a new one. On principle, the resentful man is plagued by an existential dilemma, because the defeat of his enemy compulsorily implies upsetting his identity, his agency, and his aims. Nietzsche had already stated elsewhere: "He who lives for the sake of combating an enemy has an interest in seeing that his enemy stays alive."

Although Nietzsche shows no sympathy for resentment or the resentful man, he nevertheless admits that forms of social and political justice can help diminish resentment and the power of all negative energies and forces triggered by its rising:

Everywhere where justice is practiced and justice is maintained, it is to be observed that the stronger power, when confronted with the weaker powers which are inferior to it (whether they be groups, or individuals), searches for weapons to put an end to

2 F. Nietzsche, The Genealogy of Morals..., I-10, 17.

3 F. Nietzsche, Human, All-Too-Human, trans. R. J. Hollingdale, Lincoln: University of Nebraska, 1984, Part I, Aph. 531: The life of the enemy, 183. 
the senseless fury of resentment, partly by taking the victim of resentment out of the clutches of revenge, partly by substituting for revenge a campaign of its own against the enemies of peace and order, partly by finding, suggesting, and occasionally enforcing settlements, partly by standardizing certain equivalents for injuries, to which equivalents the element of resentment is henceforth finally referred. ${ }^{4}$

Accordingly, justice is considered by Nietzsche not as a product of resentment, but as an expression of positive energy opposing it. ${ }^{5}$ Thus, he signals that the introduction of a system of law with a conception of justice re-equilibrating violations and offences contributes to reducing resentment, firstly because it enacts a system of at least partial compensation, and secondly because it facilitates creating in the subjects injured "a more and more impersonal valuation of the deed." The idea that a general and objective system of justice is applied accustoms to diminishing the feeling of vindictiveness or the desire for revenge and leads to confide in a superior (legal and political) instance, which is taken to issue a sound judgment.

\section{Max Scheler and the social roots of resentment}

Scheler also analyzes the phenomenon of resentment and connects it with a situation of weakness which affects individuals, social groups, and nations. In his view, resentment rises when 1) the sentiment of self-esteem is hurt, and 2) the subject concerned is or feels unable to restore it through a direct andopen agency. Therefore, resentment affects the vindictive person who feels constrained to hide his or her personal unease and sentiment of humiliation:

The vindictive person is always in search of objects [...]. This vengeance restores his damaged feeling of personal value, his injured honor, or it brings satisfaction for the wrongs he has endured. When it is repressed, vindictiveness leads to resentment. ${ }^{7}$

${ }^{4}$ F. Nietzsche, The Genealogy of Morals..., II-11, 64.

5 Cf. P. Stellino, "Affekte, Gerechtigkeit und Rache in Nietzsches Zur Genealogie der Moral", Friedrich Nietzsche - Geschichte, Affekte, Medien, ed. V. Gerhardt, R. Reschke, Berlin: Akademie Verlag, 2008, 247-255, here 249.

${ }^{6}$ F. Nietzsche, The Genealogy of Morals..., II-11, 65.

7 M. Scheler, Ressentiment, trans. L. Coser, in: www.mercaba.org/SANLUIS/Filosofia/ autores/Contemporánea/Scheller/Ressentiment.pdf (last accessed on 08 ${ }^{\text {th }}$ Oct. 2016), 7. 
Accordingly, resentment is connected in Scheler also with a negative and reactive attitude, which is chiefly directed to the external and influenced by it. The main feature of resentment is the persistence of that negative attitude which is accompanied with a sentiment of impotence and cannot be immediately satisfied, but has to be delayed because of the disadvantaged position or situation of the self. Powerlessness and forced inhibition provoke a constant grudge and a sense of permanent frustration. ${ }^{8}$ This can be momentarily compensated with detractive speaking and acting, which are nevertheless unsatisfying in the long run, since they performatively show the impossibility and incapacity of open talk. The logic of resentment is therefore characterized by the persistence in the negative as well as by the constant radical use of negation. Also for Scheler, the targeted "other" is perceived as the radical negative and the source of all evil and injustice. Correspondingly, the negative strategy adopted implies a systematic undermining and diminishing of their power and image, in order to progressively corrode the worthiness of their being. The good ends up by being defined only in opposition to the negative embodied by the other:

The formal structure of resentment expression is always the same: A is affirmed, valued and praised not for its own intrinsic quality, but with the unverbalized intention of denying, devaluating, and denigrating B. A is played off against B. ${ }^{9}$

Thus, the negative other is the departure and the external source of every judgement of value. Also for Scheler, resentment prevents from focusing on one's own energies and aims, and creates a relation of dependence upon the negated other.

Additionally, Scheler underlines that the motivations of resentment are not only to be sought in the psychological attitude of the subject affected, but also reside in objective specific conditions which influence their personal and social conditions. ${ }^{10}$ These conditions are in particular created in societies where the equality of right, the equality of suffrage, economic, social and educational opportunities are taken for granted, but they coexist, de facto, with significant differences of real power and disparity in the realistic chances of attaining social positions and degrees. In this sense, static and hierarchical societies, such as the premodern ones, are less subject to resentment, because their members are

${ }^{8}$ Cf. M. S. Frings, The Mind of Max Scheler, Milwaukee: Marquette University Press, 1997, 147.

9 M. Scheler, Ressentiment, 20.

${ }^{10}$ Cf. R. Olschanski, Ressentiment, Paderborn: Fink, 2015, 19-20. 
familiar with social differences and they consider them as a quasi-natural order of things. Equally, societies where social differences are smoothed and which offer a wide spectrum of possibilities and of chances are also less vulnerable, since individuals confide in sufficient and articulated opportunities of self-realization and of social recognition. By contrast, when factual differences of power obstacle or impede formal possibilities apparently given, resentment is nourished.

Another favoring condition of resentment is the presence of a system of competition taken to extremes and complemented by a situation of general instability and uncertainty. The resentful man is steadily relating to the external and establishing his values with reference to the negative "other". A social situation constantly promoting comparison and confrontation, judging, classifying, and scoring, especially if it is centered on limited targets and goods, nourishes resentment and constrains the less qualified, the less successful, or even the momentarily successful who fears losing his privileged position to constantly be put to the test. Consequently, the diminishing of the other becomes one of the most widespread and common strategies in order to prevent their possible success and to avoid the endangering of one's own position.

However, resentment increases when a person or a group doubt on their capacity of gaining or maintaining a favorable position, judge themselves to be unjustly disadvantaged, and do not believe in their realistic chances of improvement. Then, their attitude and behavior appear denigrating and detractive. They show themselves to be creative only in their original ways of belittling the other, but not in their capacity of producing, from the inside, new energies and aims.

\section{Globalization and resentment}

The question then is: can the category of resentment apply to the main constellations produced by globalization and explain any relevant negative reactions and side effects? It has to be said first that Nietzsche's attitude towards the tendencies of his time anticipating the trend to globalization is not only negative, since he also emphasizes some significant chances entailed in it.

First, the habit of comparison between different mentalities, ideas, and cultures, is only been made possible by a change in the style of life which provides sufficient opportunities to get out of the narrow and closed horizon of one's own culture which characterized past epochs and to get into contact with different perspectives and approaches to life. This allows one to gain distance and 
a more articulated and comprehensive view. Additionally, cultural comparison offers a multiplicity of solutions and ways of approaching problems which can allow for reciprocal development, provided that it is not only used to confirm one's own view, but it strengthens instead the attitude of thankfulness towards all (and also the past) cultures.

Second, the perspective of the globalized world induces for Nietzsche to overcome egoistic interests and narrow-minded aims, and confronts individuals with the fundamental challenges concerning the whole planet: "Human beings [...] can now create better conditions for the propagation of humans and for their nutrition, education and instruction, manage the earth as a whole economically, balance and employ the powers of humans in general." ${ }^{11}$

Third, the globalizing perspective introduces more dynamism, mobility, a will to discovery and transformation which well corresponds to the way of thinking of the free spirits, to their propensity to unrest, rootlessness, and allegiance to the new.

Nevertheless, the challenges of globalization and its economic, social, and political consequences not only have enhanced the possibilities of contact and profitable interweaving, but they have also contributed to destabilizing the social as well as the cultural traditional models and values, undermining the sense of security and protection they conveyed to the people, and exposing them to the uncertain and the risk of downfall. Although Nietzsche appreciates the mentality of risk and the challenges advanced by the new, he contemporarily criticizes the increasing speed and rush of modern time, time pressure, and the prevailing ideals of work, efficiency, productivity, which create unease and guilty conscience in those who prefer slowness and contemplative life.

In the globalized world, resentment characterizes a very widespread attitude and presents the features depicted by Nietzsche and Scheler on a large scale. It suits people who are not in a secure position and do not feel self-confident, but are confronted with inexplicit, deep-rooted, and haunting fears of loss and deprivation. These also often depend on a concrete worsening of condition and a connected sentiment of impotence. The negative "other", with reference to globalization, is especially embodied by two different categories: on the one hand, anonymous forces and elitist groups of power, which appear to decide about the destiny of the people, being unconcerned for their real conditions of life and their well-being; on the other hand, the "other" embodied

11 F. Nietzsche, Human All-Too-Human, Part I, Aph. 24: Possibility of progress, 25. 
by a national, racial, gender, or ethnical group, which is perceived as a real or remote threat to the security and the future of the group of belonging. ${ }^{12}$ As the category of resentment shows, the fear of a negative future condition is much more affecting than reality itself.

Thus, resentment in the globalized world affects all the people (and they are not few) who feel threatened, endangered, and overwhelmed by uncontrollable groups of power and by negative "others" who put their attained well-being at stake. They represent a dangerous concurrence because of the proximity created by mass migrations, reduction of distances, and high technology. Also in this new context, the logic which applies is that of the radical double negation, with its pertaining destructive potential. The envisaged solution requires the rejection of the negative other, which nevertheless cannot possibly be attained as desired. This provides a sentiment of powerlessness, negative attitudes and energies which focus on the indirect and hidden strategies of devaluation, detraction, and denigration. As a consequence, positive aims and targets are set in the background.

About the reasons of the growing of resentment in globalized society, they are undoubtedly, as Nietzsche and Scheler remarked, chiefly psychological, deeply residing in subjects who feel insecure, unsatisfied, surrounded by several kinds of unease and fear, and intimidated by the restless and extremely rapid changes of conditions which destabilize their feeling of security and the familiar environment. Nevertheless, some social and political elements also contribute to strengthening the feeling of resentment: the difficulty of state-sized democracies to cope with worldwide operating powerful groups, ${ }^{13}$ an extremely accentuated mentality of competition and comparison, which increases the level of capacities and requisites required and makes individuals worried and insecure about their future, a form of ranking which is nearly exclusively focused on economic and technological superiority and determines a very restricted group of winners, and a large quantity of losers with vanishing self-esteem.

Although Nietzsche and Scheler clearly dislike the resentful man, they are nevertheless keen on emphasizing the importance of justice for reducing resentment and its destructive and inhibiting consequences. Nietzsche, in particular, underlines how the idea that also less powerful and privileged individuals can

12 Cf. R. Olschanski, Ressentiment..., $188 \mathrm{ff}$.

13 Cf. R. Bellamy, "Between Cosmopolis and Community: Justice and Legitimacy in a European Union of People", Nationalism and Globalization, ed. S. Tierney, Oxford/Portland: Hart, 2015, 207-232. 
confide in an equal and fair treatment, helps reduce the feeling of diffidence and suspect which accompanies resentment and its devastating influence. The sentiment that only powerful groups and organizations can decide over the people and that there are no institutional settings and instances which are enabled and willing to defend also the weaker, nourish the sense of powerlessness, the resentment, and also the search for unequal and unfair solutions. To successfully oppose this, it has to be reckoned with the fact that the resentful man is not only the one who lost all or has no perspectives, but also and even more he who has a limited well-being which is perceived as endangered and vacillating. ${ }^{14}$

The fact of creating a new competition among the different needs and degrees of poverty and scarceness is not a desirable solution. It would only signify exasperating competition also with respect to the social welfare. Rather, a general feeling of more security, differentiated and moderate competition, the creation of real chances and the provision of a better distribution of goods (favoring the many, and possibly most of the people), could help reducing resentment and encourage the commitment to those worldwide, ecumenical aims and challenges referred to by Nietzsche. ${ }^{15}$ Also the articulation of different values and aspects to which cultures and nations can be recognized as having made differentiated, but worthwhile contributions, could imply less competition or a more constructive form of implementing it, more oriented to integrate the different positive issues than to define winners and losers, the better and the worse, the useful and the inadequate. Finally, security and change, stability and movement should be featured in a more equilibrated way, so that people do not feel overwhelmed by external subjects and factors, are enabled to exert a democratic control over them, and also maintain a basic sense of security. This would provide the reassuring feeling that the human component, and also the simple individuals, have a chance and a priority over the system.

\section{References}

Bellamy, R., "Between Cosmopolis and Community: Justice and Legitimacy in a European Union of People", Nationalism and Globalization, S. Tierney (ed.), Oxford/Portland: Hart, 2015, 207-232.

${ }^{14}$ Cf. W. Benz (ed.), Ressentiment und Konflikt, Schwalbach: Wochenschau, 2014, "Einleitung", 11.

15 Cf. F. Nietzsche, Human All-Too-Human, Part II, Aph. 179: Our agés good fortune..., 257. 
Benz, W. (ed.), Ressentiment und Konflikt, Schwalbach: Wochenschau, 2014.

Frings, M. S., The Mind of Max Scheler, Milwaukee: Marquette University Press, 1997.

Nietzsche, F., The Genealogy of Morals, trans. H. B. Samuel, New York: Boni and Liveright, 1921.

Nietzsche, F., Human, All-Too-Human, trans. R. J. Hollingdale, Lincoln: University of Nebraska, 1984.

Olschanski, R., Ressentiment, Paderborn: Fink, 2015.

Scheler, M., Ressentiment, trans. L. Coser, www.mercaba.org/SANLUIS/Filosofia/autores/ Contemporánea/Scheller/Ressentiment.pdf (4 April, 2016).

Stellino, P., "Affekte, Gerechtigkeit und Rache in Nietzsches Zur Genealogie der Moral," Nietzscheforschung, 15. JG (2008), 247-256. 